\title{
Citrullus lanatus Juice Improves Metabolic Functions in Offspring of Fructose-fed Wistar Rats
}

\author{
Julius Uchenna Asogwa ${ }^{1^{*}}$, Olufadekemi Tolulope Kunle-Alabi ${ }^{2}$, \\ Opeyemi Oreofe Akindele ${ }^{2}$ and Yinusa Raji ${ }^{2}$
}

${ }^{1}$ Laboratory for Reproductive Physiology and Developmental Programming, Department of Physiology, Faculty of Basic Medical Sciences, College of Medicine, University of Ibadan, Ibadan,

?

${ }^{2}$ Department of Physiology, Faculty of Basic Medical Sciences, College of Medicine, University of Ibadan, Ibadan, Nigeria.

\section{Authors' contributions}

This work was carried out in collaboration between all authors. Authors JUA and YR designed the study. Author JUA performed the statistical analysis, wrote the protocol and wrote the first draft of the manuscript. Author OTKA managed the analyses of the study. Author OOA managed the literature searches. All authors read and approved the final manuscript.

Article Information

DOI: $10.9734 / J A L S I / 2017 / 33815$

Editor(s):

(1) Magdy El-Sharkawy, Prof. of Internal Medicine and Nephrology, Ain Shams University, Cairo, Egypt. Reviewers:

(1) Anthony E. Ojieh, Delta State University, United States (2) Fulden Sarac, Ege University, Turkey Complete Peer review History: http://www.sciencedomain.org/review-history/19419

Original Research Article

Received $30^{\text {th }}$ April 2017 Accepted $25^{\text {th }}$ May 2017

Published $8^{\text {th }}$ June 2017

\section{ABSTRACT}

Aim: To evaluate the effects of Citrullus lanatus juice (CLJ) on fructose-induced morphometric and metabolic derangements in offspring of Wistar rats.

Study Design: On Post-Natal Day (PND) 1, morphometric indices were measured. Offspring were weaned on PND 21 and sacrificed on PND 90 under thiopentone anesthesia. Blood glucose level, serum leptin, lipid profile, oxidative status and tissue histology were assessed. Data were analyzed using ANOVA and $\mathrm{P}<0.05$ was considered statistically significant.

Place and Duration of Study: Department of Physiology, University of Ibadan, Nigeria, between February 2016 and July 2016.

Methodology: Twenty pregnant rats were randomly assigned into four groups $(n=5)$ and had their drinking water modified from Gestation Day (GD) 1-21 as follows; Control (water), Fructose $(10 \% \mathrm{w} / \mathrm{v}), \mathrm{CLJ}(50 \% \mathrm{v} / \mathrm{v})$ and Fructose + CLJ (FCLJ). 
Results: Blood glucose levels increased in both offspring from Fructose $(53.3 \hat{A} \pm 0.2 ; 69.5 \hat{A} \pm 0.2)$ compared with Control $(46 \hat{A} \pm 0.3 ; 52.3 \hat{A} \pm 0.0)$ and decreased in FCLJ $(43.3 \hat{A} \pm 0.4 ; 46 \hat{A} \pm 0.1)$ compared with Fructose. Pup's weight increased in male offspring from Fructose (5.3Â \pm 0.0$)$ compared with Control $(5.1 \hat{\mathrm{A}} \pm 0.0)$ and decreased in FCLJ $(5.1 \hat{\mathrm{A}} \pm 0.0)$ compared with Fructose. Malondialdehyde increased in male offspring from Fructose $(0.01 \hat{A} \pm 0.0)$ compared with Control $(0.009 \hat{A} \pm 0.0)$. Leptin concentration of male offspring from Fructose increased (4.8Â \pm 0.02$)$ compared with Control (3.7Â \pm 0.01$)$. Total cholesterol, triglyceride and low density lipoprotein cholesterol increased in male offspring from Fructose (153.0Â $\pm 2.3 ; 225.0 \hat{A} \pm 1.6 ; 63 \hat{A} \pm 0.4)$ compared with Control $(92.2 \hat{A} \pm 1.2 ; 135.1 \hat{A} \pm 1.6 ; 36.2 \hat{A} \pm 0.1)$. High density lipoprotein cholesterol decreased in male offspring from Fructose $(26.1 \hat{A} \pm 0.1)$ compared with Control $(40.0 \hat{A} \pm 0.1)$ and increased in both offsprings from FCLJ groups $(31.7 \hat{A} \pm 0.1 ; 32.0 \hat{A} \pm 0.2)$ compared with Fructose. Liver histology showed moderate congestion of the central venules and portal tract in male offspring from fructose group, while it appeared normal and not congested in offspring of FCLJ.

Conclusion: CLJ ameliorated the adverse effects of maternal fructose intake on blood glucose, lipid metabolism, morphometric indices and antioxidant status in offspring.

Keywords: Fructose; Citrullus lanatus juice; metabolic syndrome; oxidative stress; rat.

\section{INTRODUCTION}

In 1995, David Baker postulated that modifications in fetal nutrition and endocrine status result in developmental adaptations that permanently change structure, physiology, and metabolism, thereby predisposing individuals to metabolic, and endocrine diseases in adult lifeknown as the fetal origin hypothesis [1]. Characteristics of metabolic syndrome includes hyperlipidemia, diabetes mellitus, hypertension, hyperleptinemia, hyperinsulinemia and obesity [2]. In the last few decades, the incidence of metabolic syndrome has escalated to epidemic proportions in many countries worldwide with an elevated risk of premature mortality [3,2,4]. Diet manipulation in mothers during gestation has contributed to the development of diabetes and obesity in offspring [5]. One of the major dietary constituents that contribute to the worldwide prevalence of metabolic syndrome is the increased intake of simple sugars, especially fructose [6].

Fructose is a simple sugar that is found naturally in honey, fruits, and vegetables [7]. Over the past decades, an increase in fructose intake has been associated with high incidence of obesity [8] and metabolic disorders [9]. Diets high in dietary fructose have been implicated in the development of diabetes and alteration in metabolic status [10]. Several studies have established that fructose intake can induce leptin resistance and features of metabolic syndrome in rats $[11,12]$ and humans $[13,14]$. It has been shown experimentally that offspring of fructose- fed dams exhibited hyperglycemia [15], hyperleptinemia, and exaggerated levels of oxidative stress [16].

Citrullus lanatus (Watermelon) is the fruit of a plant originally from a vine of South Africa [17]. Studies have shown that it has the following properties: antioxidant $[18,19]$, hypoglycemic [20], anti-inflammatory [21], vasodilatory [22], antihyperlipidemic and antidiabetic activities [23]. Thus the aim of this study was to evaluate the effects of Citrullus lanatus juice on fructoseinduced pup morphometric and metabolic changes in offspring of Wistar rats.

\section{METHODOLOGY}

\subsection{Preparation of Citrullus lanatus Juice and Fructose Solution}

Citrullus lanatus fruits were obtained from a farm in Egbeda Oyo state, Nigeria. Identification was done at the Forest Research Institute of Nigeria (FRIN), Ibadan, Oyo state where FHI number 110505 was allocated. Each watermelon was washed and cut into small pieces. The thick epicarp layer and the seeds were removed. The remaining red-coloured endocarp was blended using an electric blender. A sieve was used to separate the juice from the solid particles. A $50 \%$ concentration was prepared daily by diluting watermelon juice with drinking water at ratio of 1:1 v/v [24]. A 10\% fructose (Qualikem Fine Chemical P. LTD India) solution was freshly prepared daily by dissolving $10 \mathrm{~g}$ of fructose in $100 \mathrm{ml}$ of drinking water [25]. 


\subsection{Experimental Animals}

Twenty virgin female Wistar rats $(120-150 \mathrm{~g})$ and ten proven male breeders $(250-300 \mathrm{~g})$ were obtained from the Central Animal House, College of Medicine, University of Ibadan, Nigeria. They were acclimatized for two weeks and had access to pelletized feed and water ad libitum throughout the study. All protocols were approved by the University of Ibadan Ethical Committee in charge of the use and care of animals and also in line with the use and care of animals for research purpose (NIH, 1996). The female rats were paired with the proven male breeders at ratio 2:1 (female: male). Mating was confirmed by the presence of sperm cells in the vaginal smear and the day on which sperm cells were observed was designated as Gestation Day (GD) 1 for each rat. The pregnant rats were then assigned into four groups $(n=5)$ on GD 1 , and were treated from GD 1-21 by replacing their drinking water with fructose solution and/or watermelon juice as described below:

$\begin{array}{ll}\text { Control } & \text { - drinking water } \\ \text { Fructose } & -10 \% \text { w/v Fructose } \\ & \text { solution } \\ \text { Citrullus lanatus } & -50 \% \text { v/v Citrullus } \\ & \text { lanatus juice } \\ \text { Fructose + } & -10 \% \text { w/v Fructose } \\ \text { Citrullus lanatus } & \text { solution }+50 \% \text { v/v } \\ & \text { Citrullus lanatus juice }\end{array}$

\subsection{Measurement of Pup Morphometric Indices}

Pup weight was measured with the use of sensitive weighing balance (Lisay, China), head circumferences, abdominal circumferences and crown-to-rump length were measured on a vernier calliper (Dial, India).

\subsection{Blood Glucose Level Measurement and Sacrifice}

On PND 90, the rats were fasted overnight and a drop of blood was collected from rat tails by nipping with a pair of fine scissors. Blood sugar was estimated with a glucometer (Accu-Check Active, Germany). Animals were then sacrificed under thiopentone anesthesia (500 mg/ kg i.p) [26]. Blood was collected and serum was separated for assay of leptin, lipid profile and makers of oxidative stress.

\subsection{Assays}

Triglyceride (TG), Total Cholesterol (TC), and High Density Lipoprotein (HDL) concentrations were determined spectrophotometrically using Fortress diagnostic kits. Serum leptin concentration was determined using ELISA kit (Ray Biotech, U.S).

\subsection{Biochemical Studies}

Serum malondialdehyde, superoxide dismutase, catalase and reduce glutathione were determined by the method of Rice-Evans et al. [27], Mistra and Fridovich [28], Sinha [29] and Beutler et al. [30] respectively.

\subsection{Histology of Organ}

The livers were fixed in $10 \%$ formalin for histological assessment. The procedure used was the conventional dehydration, paraffin embedding and microtomy method. Tissue was stained with Haematoxylin and Eosin ( $H$ \& $E)$ and observed under light microscope.

\subsection{Statistical Analysis}

Data were presented as mean \pm S.E.M. Means were compared using two-way ANOVA with Bonferroni post hoc test as appropriate. $\mathrm{P}<0.05$ was considered statistically significant. All analyses were performed using Graph Pad Prism (version 5) software.

\section{RESULTS}

The body weight of both male and female offsprings shows no difference among the groups (Fig. 1). There was an increase in blood glucose level of both male and female offspring from fructose-fed dams when compared with the control (Fig. 2). Blood glucose level decreased in both male and female offspring from Citrullus lanatus and fructose + Citrullus lanatus fed dams when compared with the fructose group (Fig. 2). Leptin concentration of male offspring increased in fructose group and decreased in Citrullus lanatus group compared with control and fructose group respectively (Fig. 3).

Male pups from fructose-fed dam had increased weight compared with the control group (Table 1). Pup weight of male offspring from Citrullus lanatus and fructose + Citrullus lanatus-fed dams decreased compared with the fructose group (Table 1). Female pups from fructose-fed dams had a reduced weight compared with the control (Table 1). There was an increase in head circumference, abdominal circumference and head circumference-to-abdominal circumference ratio in both male and female offsprings from 
fructose-fed dams when compared with the control (Table 1). The birth weight, head circumference, abdominal circumference and head circumference-to-abdominal circumference of male and female offspring decrease in Citrullus lanatus and fructose + Citrullus lanatusfed dams when compared with the fructose-fed dams (Table 1).

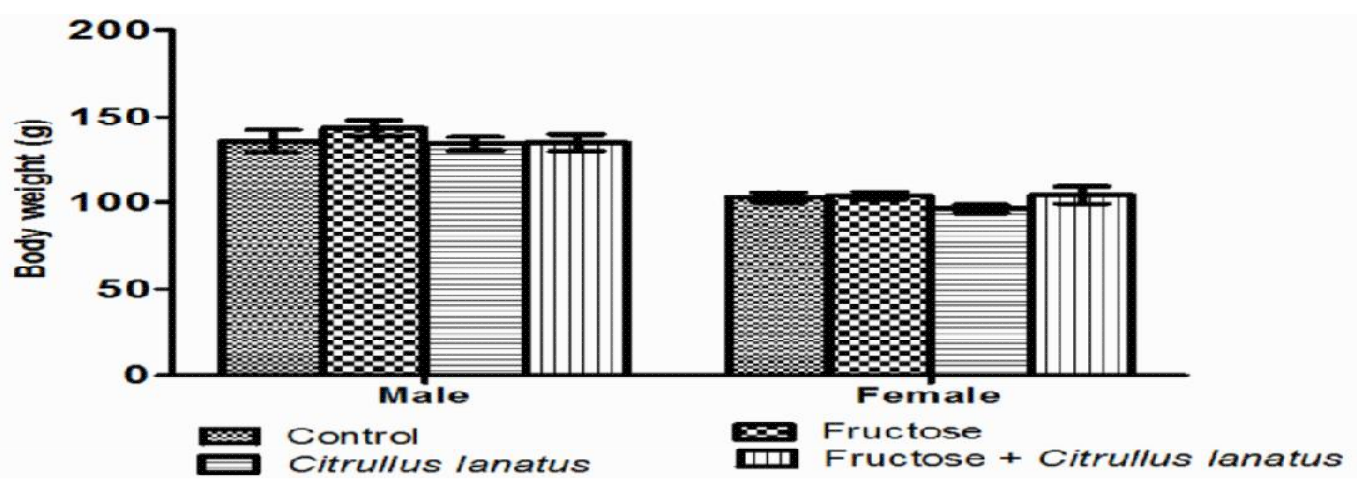

Fig. 1. Effects of maternal fructose intake and Citrullus lanatus juice on body weight of offspring at PND 90

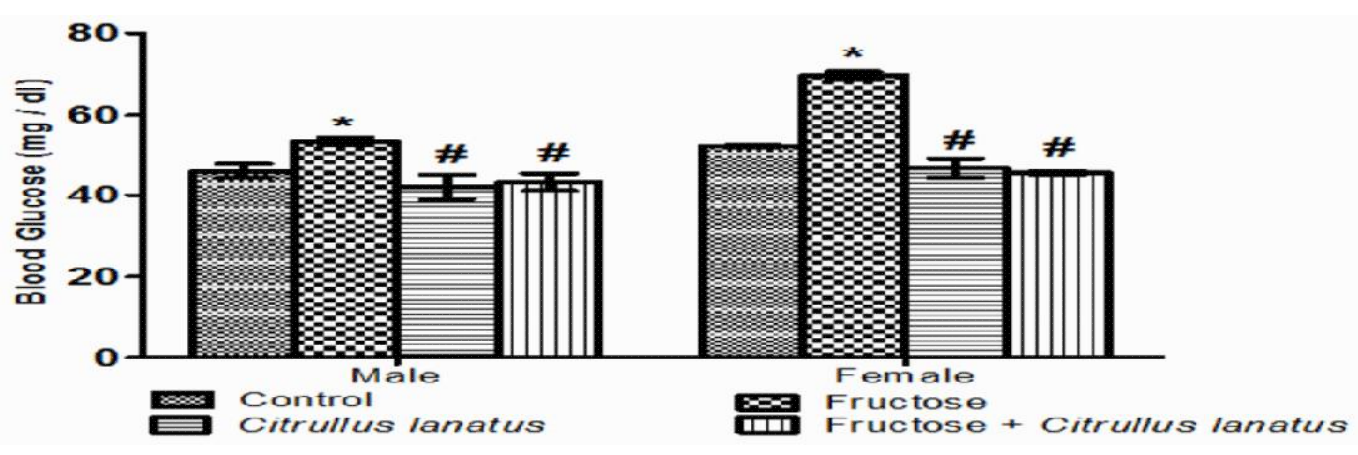

Fig. 2. Effects of maternal fructose consumption and Citrullus lanatus juice on blood glucose level of offspring at PND $\mathbf{9 0}$

Column represent mean \pm SEM. $n=5{ }^{*} P<0.05$ when compared with control group. $\# p<0.05$ when compared with fructose group

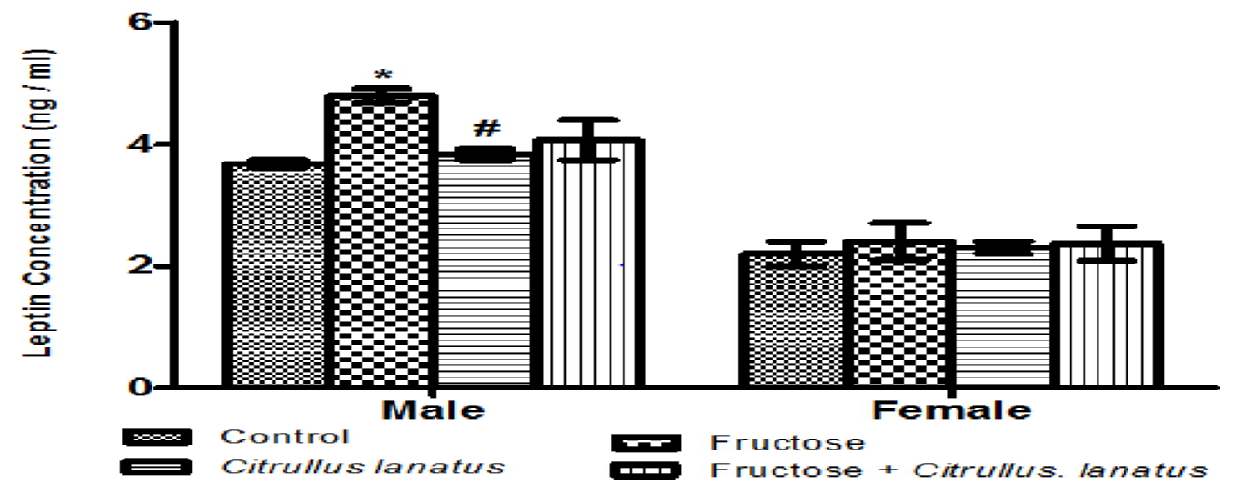

Fig. 3. Effects of maternal fructose intake and Citrullus lanatus juice on leptin concentration of male and female offspring at PND 90

Column represent mean $\pm S E M$. $n=5{ }^{*} P<0.05$ when compared with control group. $\# p<0.05$ when compared with fructose group 
Table 1. Effects of maternal fructose intake and Citrullus lanatus juice on morphometric indices of offspring at birth

\begin{tabular}{|c|c|c|c|c|}
\hline Male & Control & Fructose & Citrullus lanatus & $\begin{array}{l}\text { Fructose + } \\
\text { Citrullus lanatus }\end{array}$ \\
\hline Pup weight (g) & $5.1 \pm 0.0$ & $5.3 \pm 0.0^{*}$ & $5.1 \pm 0.0^{\#}$ & $5.1 \pm 0.0^{\#}$ \\
\hline Head circumference (mm) & $10.0 \pm 0.0$ & $10.4 \pm 0.0^{*}$ & $9.8 \pm 0.0^{\#}$ & $10.1 \pm 0.0^{\#}$ \\
\hline $\begin{array}{l}\text { Abdominal circumference } \\
(\mathrm{mm})\end{array}$ & $11.4 \pm 0.0$ & $12.4 \pm 0.0^{\pi}$ & $11.6 \pm 0.0^{\#}$ & $11.8 \pm 0.0$ \\
\hline $\begin{array}{l}\text { Head circumference-to- } \\
\text { abdominal circumference } \\
\text { ratio }(\mathrm{mm})\end{array}$ & $0.8 \pm 0.0$ & $0.9 \pm 0.0^{*}$ & $0.8 \pm 0.0^{\#}$ & $0.9 \pm 0.0$ \\
\hline Crown-rump length (cm) & $4.5 \pm 0.0$ & $4.7 \pm 0.0$ & $4.5 \pm 0.0$ & $4.5 \pm 0.0$ \\
\hline \multicolumn{5}{|l|}{ Female } \\
\hline Pup weight (g) & $5.1 \pm 0.0$ & $4.8 \pm 0.0^{*}$ & $5.1 \pm 0.0^{\#}$ & $5.0 \pm 0.0^{\#}$ \\
\hline Head circumference (mm) & $10.1 \pm 0.0$ & $10.5 \pm 0.0^{*}$ & $10.2 \pm 0.0^{\#}$ & $10.2 \pm 0.0^{\#}$ \\
\hline $\begin{array}{l}\text { Abdominal circumference } \\
(\mathrm{mm})\end{array}$ & $11.0 \pm 0.0$ & $12.2 \pm 0.0^{*}$ & $11.1 \pm 0.0^{\#}$ & $10.9 \pm 0.0^{\#}$ \\
\hline $\begin{array}{l}\text { Head circumference-to- } \\
\text { abdominal circumference } \\
\text { ratio }(\mathrm{mm})\end{array}$ & $0.82 \pm 0.004$ & $0.89 \pm 0.002^{x}$ & $0.83 \pm 0.001^{\#}$ & $0.83 \pm 0.002^{\#}$ \\
\hline Crown-rump length $(\mathrm{cm})$ & $4.5 \pm 0.0$ & $4.7 \pm 0.0$ & $4.5 \pm 0.0$ & $4.5 \pm 0.0$ \\
\hline
\end{tabular}

Relative liver weight increase in male offspring and decreased in female offspring from fructose group compared with the control group (Table 2). The pancreatic weight of male offspring increased in fructose group when compared with the control group (Table 2).

There was an increase in cholesterol, triglycerides, low density lipoprotein and very low density lipoprotein cholesterol in male offspring from fructose group compared with the control, and a reduction in these parameters in both male and female offsprings from $C$. lanatus and fructose + Citrullus lanatus groups compared with the fructose group (Table 3). High density lipoprotein cholesterol decreased in male offspring from fructose group and increased in both male and female offsprings from Citrullus lanatus and fructose + Citrullus lanatus groups compared with the fructose group (Table 3).

Superoxide dismutase activity decreased in male and female offspring from fructose group and increased in both offsprings from Citrullus lanatus group compared with control (Table 4). Catalase activities decreased in male offspring from fructose-fed dams compared with control. Superoxide dismutase, catalase and reduce glutathione level increased in both male and female offsprings from fructose + Citullus lanatus group compared with the fructose group (Table
4). Malondialdehyde levels increased in male offspring from fructose group and decrease in both offsprings from Citrullus lanatus group compared with the control. Malondialdehyde levels decreased in both offsprings from fructose + Citrullus lanatus group compared with the fructose group (Table 4).

\section{DISCUSSION}

Maternal fructose consumption is associated with the development of hyperglycemia and diabetes [31]. These conditions during pregnancy are known to affect fetal development with resultant susceptibility to health issues in adult life $[31,32,33]$. Studies in pregnant women and their offspring have suggested that exposure to maternal diabetes and obesity increases the risk of development of metabolic syndrome in the offspring $[34,35,36,37]$. In the present study, the significant increase in morphometric indices observed in the pups from fructose-fed dams on PND 1 suggest that offspring born to diabetic mother are often macrosomic $[38,39,40]$ and heavier offspring may be more predisposed to develop obesity in later life $[41,42,43]$. This confirms results from previous studies which associated the consumption of fructose-rich foods during pregnancy with the development of metabolic diseases in offspring $[31,44]$. 
Table 2. Effects of maternal fructose intake and Citrullus lanatus juice on relative organ weight offspring at PND 90

\begin{tabular}{lccll}
\hline & Control & Fructose & Citrullus lanatus & Fructose + Citrullus lanatus \\
\hline Male & & & & \\
Liver $(\mathrm{g})$ & $2.6 \pm 0.0$ & $2.8 \pm 0.0^{*}$ & $2.6 \pm 0.0$ & $2.6 \pm 0.0^{\#}$ \\
Kidney $(\mathrm{g})$ & $0.3 \pm 0.0$ & $0.3 \pm 0.0$ & $0.3 \pm 0.0$ & $0.31 \pm 0.0$ \\
Heart $(\mathrm{g})$ & $0.3 \pm 0.0$ & $0.3 \pm 0.0$ & $0.4 \pm 0.0^{*}, \#$ & $0.3 \pm 0.0$ \\
Pancreas $(\mathrm{g})$ & $0.3 \pm 0.0$ & $0.3 \pm 0.0$ & $0.4 \pm 0.0$ & $0.4 \pm 0.0$ \\
Female & & & & \\
Liver $(\mathrm{g})$ & $3.2 \pm 0.0$ & $2.4 \pm 0.0^{*}$ & $2.8 \pm 0.0^{*}, \#$ & $2.5 \pm 0.0^{*}$ \\
Kidney (g) & $0.3 \pm 0.0$ & $0.3 \pm 0.0$ & $0.3 \pm 0.0$ & $0.3 \pm 0.0$ \\
Heart (g) & $0.3 \pm 0.0$ & $0.3 \pm 0.0$ & $0.4 \pm 0.0^{*}, \#$ & $0.3 \pm 0.0^{*}$ \\
Pancreas (g) & $0.3 \pm 0.0$ & $0.4 \pm 0.0$ & $0.4 \pm 0.0$ & $0.4 \pm 0.0^{*}, \#$ \\
\hline Column represent mean \pm SEM. $n=5{ }^{*} P<0.05$ when compared with control group. \#p< 0.05 when compared with \\
\multicolumn{5}{c}{ fructose group }
\end{tabular}

Table 3. Effects of maternal fructose intake and Citrullus lanatus juice on serum lipid profile offspring at PND 90

\begin{tabular}{|c|c|c|c|c|c|}
\hline & $\begin{array}{l}\text { Cholesterol } \\
\text { (mg/dl) }\end{array}$ & $\begin{array}{l}\text { Triglyceride } \\
\text { (mg/dl) }\end{array}$ & HDL (mg/dl) & $\begin{array}{l}\mathrm{LDL} \\
(\mathrm{mg} / \mathrm{dl})\end{array}$ & $\begin{array}{l}\text { VLDL } \\
\text { (mg/dl) }\end{array}$ \\
\hline \multicolumn{6}{|l|}{ Male } \\
\hline Control & $92.2 \pm 1.2$ & $135.1 \pm 1.6$ & $39.5 \pm 0.1$ & $36.2 \pm 0.1$ & $27.0 \pm 0.3$ \\
\hline Fructose & $152.5 \pm 2.3^{*}$ & $224.8 \pm 1.6^{*}$ & $26.1 \pm 0.2^{*}$ & $62.8 \pm 0.4^{*}$ & $49.0 \pm 0.4^{*}$ \\
\hline Citrullus lanatus & $99.9 \pm 0.3^{\#}$ & $140.2 \pm 0.5$ & $43.2 \pm 0.2^{*}, \#$ & $31.5 \pm 0.3^{\#}$ & $28.0 \pm 0.1^{\#}$ \\
\hline $\begin{array}{l}\text { Fructose }+ \text { Citrullus lanatus } \\
\text { Female }\end{array}$ & $114.9 \pm 2.0^{\#}$ & $156.8 \pm 0.3^{\#}$ & $31.7 \pm 0,1^{*}, \#$ & $37.2 \pm 0.1^{\#}$ & $31.4 \pm 0.1^{\#}$ \\
\hline Control & $126.4 \pm 1.4$ & $94.2 \pm 1.6$ & $30.4 \pm 0.1$ & $62.6 \pm 0.2$ & $18.8 \pm 0.3$ \\
\hline Fructose & $118.4 \pm 0.8$ & $116.5 \pm 2.1$ & $30.0 \pm 0.2$ & $66.0 \pm 0.4$ & $23.3 \pm 0.4$ \\
\hline Citrullus lanatus & $115.7 \pm 0.3$ & $107.7 \pm 0.1^{\#}$ & $35.2 \pm 0.1^{*}$ & $46.6 \pm 0.1^{\#}$ & $21.5 \pm 0.0$ \\
\hline Fructose + Citrullus lanatus & $97.0 \pm 0.7^{*}, \#$ & $114.0 \pm 4.2$ & $32.0 \pm 0.2^{\#}$ & $53.3 \pm 0.2$ & $22.8 \pm 0.8$ \\
\hline
\end{tabular}

Table 4. Effects of maternal high fructose intake and Citrullus lanatus juice on serum oxidative status of offspring at PND 90

\begin{tabular}{|c|c|c|c|c|}
\hline & Control & Fructose & Citrullus lanatus & Fructose + Citrullus lanatus \\
\hline \multicolumn{5}{|c|}{ 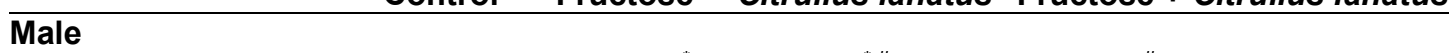 } \\
\hline MDA (U/mg protein) & $0.01 \pm 0.0$ & $0.01 \pm 0.0^{*}$ & $0.01 \pm 0.0^{*}, \#$ & $0.01 \pm 0.0^{\#}$ \\
\hline SOD (U/mg protein) & $7.9 \pm 0.01$ & $5.6 \pm 0.0^{*}$ & $11.1 \pm 0.1^{*}, \#$ & $8.0 \pm 0.0^{\#}$ \\
\hline Catalase (IU/L) & $0.5 \pm 0.0$ & $0.4 \pm 0.0$ & $0.5 \pm 0.0$ & $0.5 \pm 0.0^{\#}$ \\
\hline $\mathrm{GSH}$ (U/mg protein) & $30.3 \pm 0.1$ & $27.0 \pm 0.4$ & $40.9 \pm 0.0^{\star, \#}$ & $34.0 \pm 0.2^{\#}$ \\
\hline Female & & & & \\
\hline MDA (U/mg protein) & $0.01 \pm 0.0$ & $0.01 \pm 0.0$ & $0.002 \pm 0.0^{*}, \#$ & $0.004 \pm 0.0^{\#}$ \\
\hline SOD (U/mg protein) & $3.6 \pm 0.04$ & $2.7 \pm 0.04^{*}$ & $4.9 \pm 0.03^{x, \#}$ & $4.3 \pm 0.07^{\#}$ \\
\hline Catalase (IU/L) & $0.3 \pm 0.0$ & $0.3 \pm 0.0$ & $0.4 \pm 0.0$ & $0.3 \pm 0.0$ \\
\hline $\mathrm{GSH}$ (U/mg protein) & $15.0 \pm 0.1$ & $11.1 \pm 0.1$ & $27.3 \pm 0.1^{*}, \#$ & $21.0 \pm 0.0^{x \#}$ \\
\hline
\end{tabular}

Superoxide dismutase is a metalloprotein and is the first enzyme involved in the antioxidant defence by lowering the steady state level of superoxide anion [45]. It is the only enzymatic 
system quenching superoxide anion to oxygen and hydrogen peroxide and plays a significant role against oxidant stress [46]. Catalase is a hemoprotein, localized in the peroxisomes or the microperoxisomes. This enzyme catalysis the decomposition of hydrogen peroxide to water and oxygen [47] and thus protecting the cell from oxidative damage by hydrogen peroxide and hydroxyl radical. In this study, the low level of superoxide dismutase activity in both male and female offspring of fructose-fed dams indicates that there was an accumulation of superoxide radicals in the serum of the offsprings. Similarly, the reduction of catalase activities observed in the serum of male offspring from fructose-fed dams reflects the inability of tissues in the animals to eliminate hydrogen peroxide produced by the inactivation of the enzymes probably due to the excess generation of reactive oxygen species [48]. Thus, superoxide dismutase and

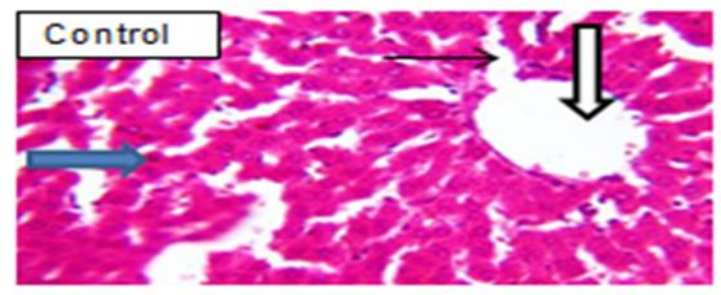

The central venules appeared normal are not congested (White arrows). The sinusoids appeared normal (slender arrow) without infiltration of inflammatory cells. The hepatocytes showed normal morphology (blue arrow)

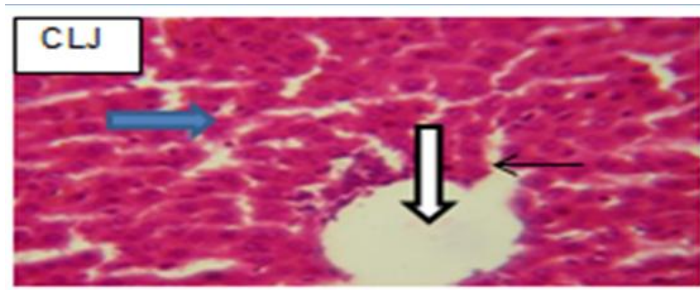

The central venues appear normal are not congested (white arrow). The sinusoids appeared normal (slender arrow) without infiltration of inflammatory cells. The hepatocytes showed normal morphology blue arrow) catalase function mutually as enzymatic antioxidative defense mechanism to counter the deleterious effect of reactive oxygen species. It thus suggests that reduction in the level of these enzymes can lead to oxidative stress in the offspring of fructose-fed dams. However, the offspring from Citrullus lanatus and fructose + Citrullus lanatus-fed dams had an increase in the activity of superoxide dismutase. These may be due to the high level of phytonutrient (including lycopene) present in Citrullus lanatus [49]. Study has shown that lycopene a highly effective antioxidant acts as a strong free radical scavenger [50]. In this context, the micronutrient antioxidant contents, especially lycopene, in $50 \%$ Citrullus lanatus juice, accumulate in the serum of the offspring and counteract the deleterious effects of free radicals generated by maternal fructose consumption through activation of oxygen molecules.

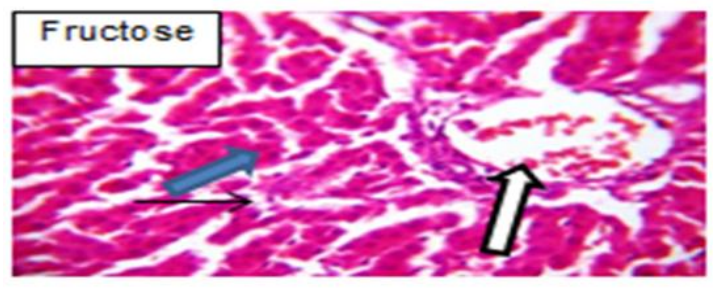

The central venues showed severe congested (white arrows). The sinusoids showed mild infiltration of inflammatory cells (slender arrow). The hepatocytes showed normal morphology (blue arrow)

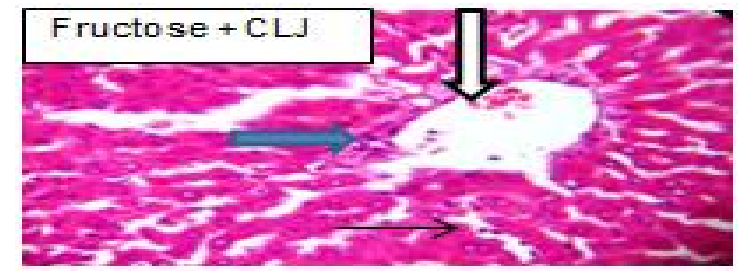

The central venues showed mild congestion (white arrow). The sinosoids showed moderate infiltration of inflammatory cells (slender arrow). The hepatocytes showed normal morphology (blue arrow)

Fig. 4. Effects of matemal fructose intake and Citrullus lanatus juice on the liver histology of male offspring at PND 90

( $H$ \& E. Magnification X400) 


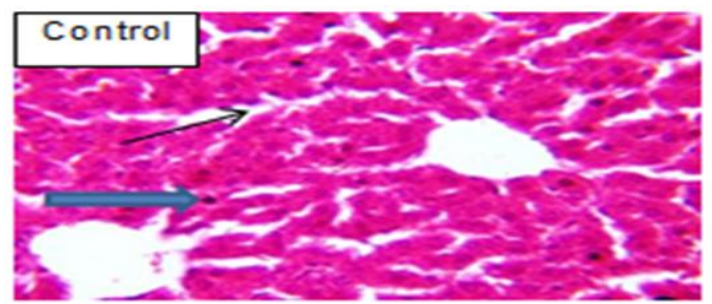

The sinusoids appeared normal (slender arrow) without infiltration of inflammatory cells. The hepatocytes showed normal morphology (blue arrow)

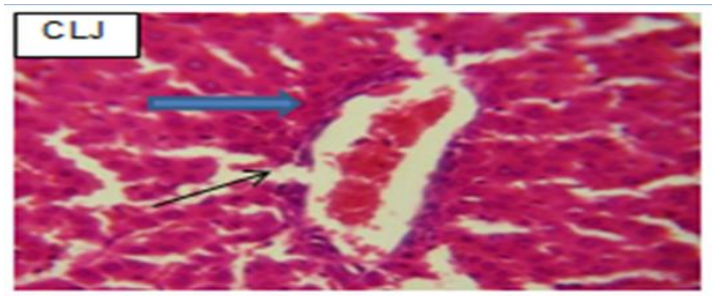

The sinusoids appear normal (slender arrow without infiltration of inflammatory cells. The hepatocytes show normal morphology (blue arrow)

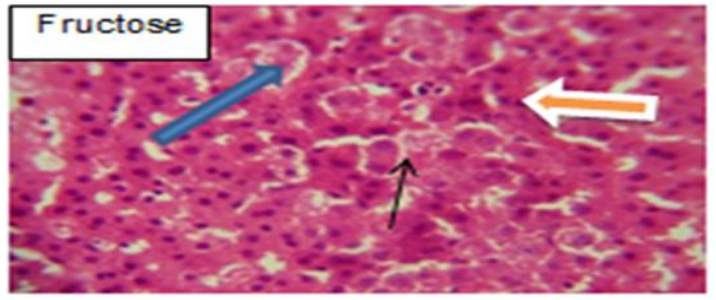

The sinusoids showed severe infiltration of infiammatory cells. There are few hepatocytes showing vacuolated cytoplasms (black arrow), others show normal morphology (yellow arrow)

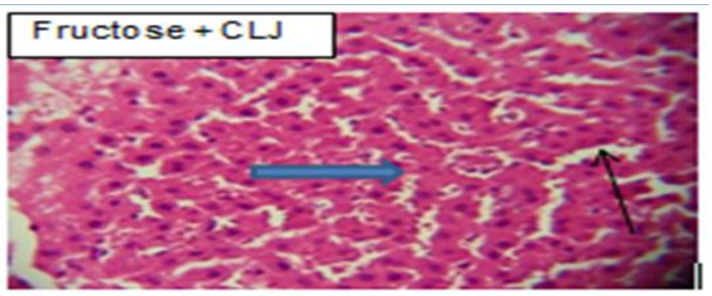

The sinusoids showed moderate infiltration of inflammatory cells (Slender arrow). The hepatocytes show normal morphology (blue arrow)

Fig. 5. Effects of matemal fructose intake and Citrullus lanatus juice on the liver histology of female offspring at PND 90

$H$ \& E. Magnification X400

Malondialdehyde is a product of lipid peroxidation and a measure of free radical generations [51]. The elevated malondialdehyde levels observed in the serum of male offspring from fructose-fed dams in this study suggests the accumulation of superoxide radicals and hydrogen peroxide in the serum of male offspring, thereby making them prone to oxidative stress [52]. This is in line with the work of Lourdes et al. [16] which reported that maternal fructose intake induces oxidative stress in male, but not in female offspring. Supplementation with $50 \%$ Citrullus lanatus juice restored the activities of intracellular antioxidant enzymes in serum of the offspring following maternal fructose consumption. Thus, phytochemical antioxidants contents in 50\% Citrullus lanatus juice may possibly contribute to the efficiency of intracellular antioxidant defense system by scavenging free radicals which induced oxidative damage. This support the study conducted by Asita and Molise [53] which reveals that Citrullus lanatus juice contains higher content of carotenoids such as lycopene and has proven to scavenge free radicals thus inhibit lipid peroxidation.

Reduced glutathione has been reported to have protective roles against oxidative stress through scavenging hydroxyl radical and singlet oxygen directly detoxifying hydrogen peroxide and lipid peroxides and also regenerate important antioxidants, Vitamins $C$ and $E$, back to their active forms [54]. The depletion of reduced glutathione may be one of the reasons for the increased vulnerability added to freeradicalinduced damage. Therefore, the decreased in reduced glutathione level in serum of offsprings from fructose-fed dam in the present study suggests that it toxic effects may expose the offspring to damage. However, supplementation with $50 \%$ Citrullus lanatus juice significantly increase the levels of reduced glutathione in offspring from fructose-fed dams. The present results were in line with a study conducted by Saada et al. [55] which highlighted that pretrearment with lycopene, which is present in Citrullus lanatus significantly improve the 
antioxidant status and helped in reducing oxidative damage. It is therefore suggested that Citrullus lanatus juice contains a free radical scavenging activity which could exert a beneficial action against pathological alteration caused by the presence of superoxide anion and hydroxyl radical [56]. This action could involve the mechanism of superoxide anion in relation to the scavenging activity.

The elevated blood glucose level in both offsprings from the fructose group confirms results from previous studies that consumption of fructose results in the development of hyperglycemia and diabetes [31]. These suggested that the increased glucose in the fetal circulation, derived from maternal plasma fructose via the placenta, is associated with upregulation of gluconeogenesis in the liver of the offspring [57]. It may also be as a result of decreased insulin sensitivity, peripheral utilization of glucose, glycogenesis and increased glycogenolysis [57]. The elevated blood glucose level may be partly responsible for the increased liver weight observed in the offspring of fructose-fed groups. It can also be attributed to change in hepatic glycogen storage [58]. The rats which received both fructose and Citrullus lanatus juice were normo-glycemic suggesting that Citrullus lanatus juice has the ability to prevent development of hyperglycemia in offspring from fructose-fed dams.

The increased concentration of triglyceride, cholesterol, low density lipoprotein cholesterol and very low density lipoprotein cholesterol in adult male offspring from fructose-fed dams suggest that maternal fructose intake during pregnancy may cause hypercholesterolemia in offspring. This could be attributed to the stimulation of hepatic lipogenesis and inhibition of fatty acid oxidation by fructose [59]. Male offspring from the fructose + Citrullus lanatus-fed dams showed normo-cholesterolemic. Thus, Citrullus lanatus juice can be helpful in the prevention of hypercholesterolemia in male offspring from fructose-fed dams. The observed oxidative stress as demonstrated by increased MDA, reduced SOD, catalase and GSH may be responsible for the hyperglycemia and hypercholesterolemia [60]. It is suggested that lycopene, a hypoglycemic and hypocholesterolemic agent present in Citrullus lanatus have the ability to scavenge free radicals at cellular level due to it attachment in cell membrane thereby preventing hyperglycemia and hypercholesterolemia $[61,62]$.
The elevated level of leptin in male offspring from fructose-fed dam could also indicate leptin resistance [63]. Since insulin stimulates adipogenesis and leptin production in adipocytes, and leptin inhibits the production of insulin in pancreatic $\beta$-cells. A prolonged elevation of plasma leptin levels would result in dysregulation of the adipoinsular axis and a corresponding failure to suppress insulin secretion [64]. Since the progeny from fructosefed mothers were already leptin resistant when they were fetuses [64], the male offspring of fructose-fed pregnant rats could present a vicious circle (leptin resistance, hypersecretion of insulin, and increasing insulin resistance) $[57,65,66]$. However, supplementation with Citrullus lanatus ameliorated these changes in male offspring.

\section{CONCLUSION}

Offsprings of fructose-fed mother can be programmed to develop metabolic disorders. However, treatment with Citrullus lanatus juice ameliorated these effects showing that Citrullus lanatus juice can be helpful in preventing the development of metabolic disorders later in life.

\section{ACKNOWLEDGEMENT}

The authors are grateful to the research assistance of Miss Oladipo Taiwo Dorcas of Department of Biochemistry University of Ibadan, Nigeria.

\section{COMPETING INTERESTS}

Authors have declared that no competing interests exist.

\section{REFERENCES}

1. Barker DJ. Fetal origins of coronary heart disease. BMJ. 1995;311:171-174.

2. Isomaa B, Almgren $\mathrm{P}$, Tuomi T, Forsen B, Lahti K, Nissen M, et al. Cardiovascular morbidity and mortality associated with the metabolic syndrome. Diabetes Care. 2001;24(4):683-689.

3. Trevisan M, Liu J, Bahsas FB, Menotti A. Syndrome $X$ and mortality: A populationbased study. American Journal of Epidemiology. 1998;148:958-966.

4. Hamer $M$, Stamatakis E. Low-dose physical activity attenuates cardiovascular disease mortality in men and women with 
clustered metabolic risk factors. Circ Cardiovasc Qual Outcomes. 2012;5:494499.

5. Alzamendi A, Castrogiovanni D, Gaillard RC, Spinedi E, Giovambattista A. Increased male offspring's risk of metabolic-neuroendocrine dysfunction and overweight after fructose-rich diet intake by the lactating mother. Endocrinology. 2010;151(9):4214-4223.

6. Firoozeh Hosseini-Esfahani, Zahra Bahadoran, Parvin Mirmiran, Somayeh Hosseinpour-Niazi, Farhad Hosseinpanah, Fereidoun Azizi. Dietary fructose and risk of metabolic syndrome in adults. Nutrition Metabolism. 2011;8:50.

7. Henry RR, Crapo PA, Thorburn AW. Current issues in fructose metabolism. Annual Review Nutrition. 1991;11:21-39.

8. Bray GA, Nielsen SJ, Popkin BM. Consumption of high-fructose corn syrup in beverages may play a role in the epidemic of obesity. American Journal of Clinical Nutrition. 2004;79:537-543.

9. Johnson RJ, Segal MS, Sautin Y. Potential role of sugar (fructose) in the epidemic of hypertension, obesity and the metabolic syndrome, diabetes, kidney disease, and cardiovascular disease. The American Journal of Clinical Nutrition. 2007;86(4): 899-906.

10. Stanhope KL, Schwarz JM, Keim NL. Consuming fructose-sweetened, not glucose-sweetened, beverages increases visceral adiposity and lipids and decreases insulin sensitivity in overweight/obese humans. Journal of Clinical Investigation. 2009;119(5):1322-1334.

11. Taghibiglou $\mathrm{CH}$, Carpentier $\mathrm{A}$, Van Iderstine SC. Mechanisms of hepatic very low-density lipoprotein overproduction in insulin resistance. The Journal of Biological Chemistry. 2000;275(12):84168425.

12. Johnson RJ, Perez-Pozo SE, Sautin YY. Hypothesis: Could excessive fructose intake and uric acid cause type 2 diabetes? Endocrine Reviews. 2009;30(1): 96-116.

13. Stanhope KL, Havel PJ. Fructose consumption: Recent results and their potential implications. Annals of the New York Academic of Science. 2010;1190:1524.

14. Tappy L, Le KA. Metabolic effects of fructose and the worldwide increase in obesity. Physiology Review. 2010;90:2346.

15. Jen $\mathrm{KL}$, Rochon $\mathrm{C}$, Zhong SB, Whitcomb $\mathrm{L}$. Fructose and sucrose feeding during pregnancy and lactation in rats changes maternal and pup fuel metabolism. Journal of Nutrition. 1991;121:1999-2005.

16. Lourdes Rodríguez, Paola Otero, María I Panadero, Silvia Rodrigo, Juan J ÁlvarezMillán, Carlos Bocos. Maternal fructose intake induces insulin resistance and oxidative stress in male, but not female, offspring. Journal of Nutrition and Metabolism. 2015;158091.

17. Chomicki G, Renner SS. Watermelon origin solved with molecular phylogenetics including Linnaean material: Another example of museomics. New Phytologist. 2014;205(2):526-532.

18. Wu G, Collins JK, Perkins-Veazie P, Siddiq M, Dolan KD, Kelly KA, et al. Dietary supplementation with watermelon pomace juice enhances arginine availability and ameliorates the metabolic syndrome in Zucker diabetic fatty rats. Journal of Nutrition. 2007;137(12):26802685.

19. Oseni OA, Odesanmi OE, Oladele FC. Antioxidative and antidiabetic activities of watermelon (Citrullus lanatus) juice on oxidative stress in alloxan-induced diabetic male wistar albino rats. Nigerian Medical Journal. 2015;56(4):272-277.

20. Omigie IO, Agoreyo FO. Effects of Watermelon (Citrullus lanatus) seed on blood glucose and electrolyte parameters in diabetic wistar rats. Journal of Applied Science and Environmental Management. 2014;18(2):231-233.

21. Altas S, Kizil G, Kizil M, Ketani A, Haris PI. Protective effect of Diyarbakir watermelon juice on carbon tetrachloride-induced toxicity in rats. Food Chemistry and Toxicology. 2011;49:2433-2438.

22. Figueroa $A$, Sanchez-Gonzalez MA, Perkins-Veazie PM, Arjmandi BH. Effects of watermelon supplementation on aortic blood pressure and wave reflection in individuals with prehypertension: A pilot study. American Journal of Hypertens. 2011;24:40-44.

23. Chinmay D Deshmukh, Anurekha Jain. Antidiabetic and antihyperlipidemic effect of Citrullus lanatus seed in rats. International Journal of Pharmacy and Pharmaceutical Sciences. 2015;7:10. 
24. Mohd KAM, Muhamad IM, Ainul MZ, Hairil RAZ, Wan MM. Watermelon (Citrullus lanatus (Thunb.) Matsum. and Nakai) juice modulates oxidative damage induced by low dose X-Ray in mice. BioMed Research International. 2014;512834.

25. Vickers MH, Clayton ZE, Yap C, Sloboda DM. Maternal fructose intake during pregnancy and lactation alters placental growth and leads to sex-specific changes in fetal and neonatal endocrine function. Endocrinology. 2011;152(4):1378-1387.

26. Pereda J, Gómez-Cambronero L, Alberola A, Fabregat G, Cerdá M, Escobar J, et al. Coadministration of pentoxifylline and thiopental causes death by acute pulmonary oedema in rats. British Journal Pharmacology. 2006;149(4):450-455.

27. Rice-Evans C, Burdom R. Free radicallipid interactions and their pathological con-sequences. Progress in Lipid Research. 1993;32(1):71-110.

28. Misra HP, Fridovich I. The role of superoxide anion in the auto-oxidation of epinephrine and a simple assay for superoxide dismutase. Journal of the Biological Chemistry. 1972;247(10):31703175.

29. Sinha AK. Calorimetric assay of catalase. Analytical Biochemistry. 1972;47(2):389394.

30. Beutler E, Duron O, Kelly BM. Improved method for the determination of blood glutathione. Journal of Laboratory and Clinical Medicine. 1963;61:882-888.

31. Regnault RH Timothy, Sheridan Gentili, Ousseynou Sarr, Carla R Toop, Deborah $M$ Sloboda. Fructose, pregnancy and later life impacts. British Journal of Clinical Pharmacology. 2013;40(11):824-837.

32. Lourdes Rodríguez, María I Panadero, Núria Roglans, Paola Otero, Juan J Álvarez-Millán, Juan C Laguna, et al. Fructose during pregnancy affects maternal and fetal leptin signaling. The Journal of Nutritional Biochemistry. 2013;24(10):1709-1716.

33. Lourdes Rodríguez, Paola Otero, María I Panadero, Silvia Rodrigo, Juan J ÁlvarezMillán, Carlos Bocos. Maternal fructose intake induces insulin resistance and oxidative stress in male, but not female, offspring. Journal of Nutrition and Metabolism. 2015;158091.

34. Pettitt DJ, Baird HR, Aleck KA, Bennett $\mathrm{PH}$, Knowler WC. Excessive obesity in offspring of Pima Indian women with diabetes during pregnancy. New England Journal of Medicine. 1983;308:242-245.

35. Catalano PM, Kirwan JP, Haugel-De Mouzon S, King J. Gestational diabetes and insulin resistance: Role in short- and long-term implications for mother and fetus. Journal of Nutrition. 2003;133: 1674S-1683S

36. Catalano PM, Presley L, Minium J, Hauguel-De Mouzon S. Fetuses of obese mothers develop insulin resistance in utero. Diabetes Care. 2009;32:1076-1080.

37. Poston L. Developmental programming and diabetes - The human experience and insight from animal models. Best Practice and Research. Clinical Endocrinology and Metabolism. 2010;24:541-552.

38. Ehrenberg HM, Mercer BM, Catalano PM. The influence of obesity and diabetes on the prevalence of macrosomia. American Journal Obstetrics and Gynecology. 2004;191:964-968.

39. Metzger BE, Lowe LP, Dyer AR, Trimble ER, Chaovarindr U, Coustan DR, et al. Hyperglycemia and adverse pregnancy outcomes. New England Journal of Medicine. 2008;358:1991-2002.

40. Segregur J, Bukovic D, Milinovic D, Oreskovic S, Pavelic J, Zupic T, et al. Fetal macrosomia in pregnant women with gestational diabetes. Collegium Antropologicun. 2009;33:1121-1127.

41. Boney CM, Verma A, Tucker R, Vohr BR. Metabolic syndrome in childhood: Association with birth weight, maternal obesity, and gestational diabetes mellitus. Pediatrics. 2005;115:290-296.

42. Pirkola J, Pouta A, Bloigu A, Hartikainen $A L$, Laitinen J, Jarvelin MR, et al. Risks of overweight and abdominal obesity at age 16 years associated with prenatal exposures to maternal prepregnancy overweight and gestational diabetes mellitus. Diabetes Care. 2010;33:11151121.

43. Sparano S, Ahrens W, De Henauw S, Marild S, Molnar D, Moreno LA, et al. Being macrosomic at birth is an independent predictor of overweight in children: Results from the IDEFICS study. Maternal Child Health Journal. 2013;17(8):1373-1381.

44. Saad AF, Dickerson J, Kechichian TB, Yin H, Gamble P, Salazar A, et al. Format: abstract, high fructose diet in pregnancy 
leads to fetal programming of hypertension, insulin resistance, and obesity in adult offspring. American Journal Obstetrics and Gynecology. 2016;215(3): 378.e1-378.e6

45. Adewale Olabiyi Folorunso, Olatunji Olusola Isaac, Makinwa Temitope Tunmise, Oguntibeju Oluwafemi Omoniyi. Palm oil and ground nut oil supplementation effects on blood glucose and antioxidant status in alloxan-induced diabetic rats. Pakistan Journal of Pharmaceutical Sciences. 2016;29(1):8387.

46. Meydan D, Gursel B, Bilgici B, Can B, Ozbek N. Protective effect of lycopene against radiation induced hepatic toxicity in rats. Journal of International Medical Research. 2011;39(4):1239-1252.

47. Murray RK, Granner DK, Mayes PO, Rodwell VW. Harper's illustrated biochemistry. 26th Edn., Appleton and Lange Medical Publication/McGraw Hill, USA; 2003.

48. Breiner LH. Molecular mechanisms of oxygen radical carcinogenesis and mutagenesis: The role of DNA base damage. Molecular. Carcinogenesis. 1990;3:188-197.

49. Tarazona-Díaz MP, Viegas J, MoldaoMartins M, Aguayo E. Bioactive compounds from flesh and byproduct of fresh-cut watermelon cultivars. Journal of the Science of Food and Agriculture. 2011;91(5):805-812.

50. Perkins-Veazie P, Collins JK, Pair SD, Roberts W. Lycopene content differs among red-fleshed watermelon cultivars. Journal of the Science of Food and Agriculture. 2001;81(10):983-987.

51. Adebayo $\mathrm{AH}$, Abolaji $\mathrm{AO}$, Kela R, Ayepola OO, Olorunfemi TB, Taiwo OS. Antioxidant activities of the leaves of Chrysophyllum albidum G. Pakistan Journal of Pharmaceutical Sciences. 2011;24:545551.

52. Edwin Ho, Keyvan Karimi Galougahi, ChiaChi Liu, Ravi Bhindi, Gemma A Figtree. Biological markers of oxidative stress: Applications to cardiovascular research and practice. Redox Biology. 2013;483491.

53. Asita AO, Molise T. Antimutagenic effects of red apple and watermelon juices on cyclophosphamide induced genotoxicity in mice. African Journal of Biotechnology. 2011;10(77):17763-17768.

54. Valko M, Leibfritz D, Moncol J, Cronin MTD, Mazur M, Telser J. Free radicals and antioxidants in normal physiological functions and human disease. International Journal of Biochemistry and Cell Biology. 2007;39(1):44-84.

55. Saada HN, Rezk RG, Eltahawy NA. Lycopene protects the structure of the small intestine against gamma-radiationinduced oxidative stress. Phytotherapy Research. 2010;24(2):204-208.

56. Raghavan B, Kumari SK. Effect of Terminalia arjuna stem bark on antioxidant status in liver and kidney of alloxan diabetic rats. Indian Journal of Physiology and Pharmacology. 2006;50(2):133-142.

57. Rawana S, Clark K, Zhong S, Buison A, Chackunkal S, Jen KL. Low dose fructose ingestion during gestation and lactation affects carbohydrate metabolism in rat dams and their offspring. Journal of Nutrition. 1993;123:2158-2165.

58. Bar A. Characteristics and significance of $D$-tagatose-induced liver enlargement in rats: An interpretative review. Regulatory Toxicology and Pharmacology. 1999;29: 83-93.

59. Tappy L, Le KA. Metabolic effects of fructose and the worldwide increase in obesity. Physiology Review. 2010;90:2346.

60. Ratnam DV, Ankola DD, Bhardwaj V, Sahana DK, Kumar MNVR. Role of antioxidants in prophylaxis and therapy: A pharmaceutical perspective. Journal of Controlled Release. 2006;113(3):189-207.

61. Marinova D, Ribarova F, Atanassova M. Total phenolics and total flavonoids in Bulgarian fruits and vegetables. Journal of the University of Chemical Technology Metallurgy. 2005;40:255-260.

62. Fisher J, Frazee LA. Update on prostate cancer chemoprevention. Journal of Human Pharmacology and Drug Therapy. 2006;26:353-359.

63. Srinivasan $M$, Dodds $C$, Ghanim $H$. Maternal obesity and fetal programming: effects of a highcarbohydrate nutritional modification in the immediate postnatal life of female rats. The American Journal of Physiology-Endocrinology and Metabolism. 2008;295(4):895-903. 
64. Vickers MH, Reddy S, Ikenasio BA, Breier $\mathrm{BH}$. Dysregulation of the adipoinsular axis-a mechanism for the pathogenesis of hyperleptinemia and adipogenic diabetes induced by fetal programming. Journal of Endocrinology. 2001;170(2): 323-332.

65. Rodríguez L, Panadero MI, Roglans $\mathrm{N}$. Fructose during pregnancy affects maternal and fetal leptin signaling. The
Journal of Nutritional Biochemistry. 2013;24(10):1709-1716.

66. Shapiro A, Mu W, Roncal C, Cheng KY, Johnson RJ, Scarpace PJ. Fructoseinduced leptin resistance exacerbates weight gain in response to subsequent high-fat feeding. The American Journal of Physiology-Regulatory Integrative and Comparative Physiology. 2008;295(5): 1370-1375.

(c) 2017 Asogwa et al.; This is an Open Access article distributed under the terms of the Creative Commons Attribution License (http://creativecommons.org/licenses/by/4.0), which permits unrestricted use, distribution, and reproduction in any medium, provided the original work is properly cited.

Peer-review history:

The peer review history for this paper can be accessed here: http://sciencedomain.org/review-history/19419 